\title{
Knowledge and practices regarding child rearing and its association with literacy among married women in a rural area of Tamil Nadu, India
}

Rizwan Suliankatchi Abdulkader, Ankita Kankaria, Ronald Roy ${ }^{1}$, Vinoth Gnana Chellaiyan', Pradip Kharya,

Ravi Prakash Upadhyay², Palanivel Chinnakali ${ }^{3}$

Center for Community Medicine, All India Institute of Medical Sciences, New Delhi, ${ }^{1}$ Madurai Medical College, Madurai, Tamil Nadu, ${ }^{2}$ Department of Community Medicine, Vardhman Mahavir Medical College and Safdarjang Hospital, New Delhi, ${ }^{3}$ Indira Gandhi

Medical College and Research Institute, Puducherry, India

Address for the Correspondence:

Dr. S. A. Rizwan

Center for Community Medicine, All India Institute of Medical Sciences, New Delhi - 110 029, India.

E-mail: sarizwan1986@gmail.com

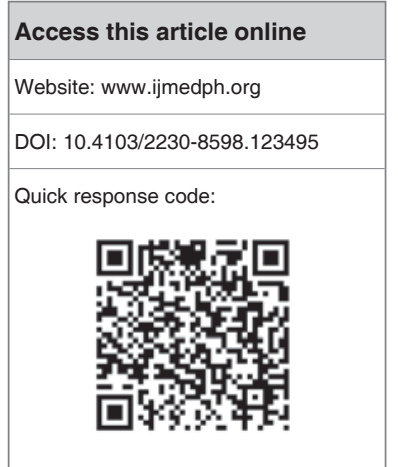

Background: India contributes a large proportion to global under-five child mortality. One of the determinants of child morbidity and mortality is the "child rearing practices." Socio-economic environment, child rearing practices and nutritional status play a synergistic role. Materials and Methods: Information was collected by exit interviews from married women attending out-patient departments of three primary health centers. Data was collected during December, 2009 using pretested questionnaire Married women in reproductive age group with youngest child in the age group of 1-5 years were eligible for inclusion. To assess the child rearing knowledge and practices (CRKP), a composite score was calculated based on 10 variables and categorized into satisfactory and unsatisfactory. Results: A total of 100 eligible married women were included in the study. About half of the women were in the age group of $25-35$ years, $80 \%$ belonged to social class $\mathrm{V}$ and VI majority $(63 \%)$ were literate and $70 \%$ had $\geq 2$ children. With the increase in literacy status, there was the increase in proportion of women who had satisfactory CRKP and decrease in proportion of women who had given pre-lacteal feed. Among women who had three children, 15 out of 39 (38\%) had fully immunized their first child as compared with 25 out of $39(64 \%)$ for the second child and 38 out of $39(97 \%)$ for the third child. Immunization coverage increased as the birth order increased. Conclusion: Mothers' education has a significant role in determining her child rearing practices, which in turn would lead better child survival.

Key words: Child rearing practices, India, maternal education, rural

\section{INTRODUCTION}

India accounts for $24 \%$ of all under-five child deaths that occur globally. ${ }^{[1]}$ Although India has achieved impressive gains in child survival over the last two decades, at the current pace the country is unlikely to achieve the millennium development goal 4, which aims to reduce under-five mortality by two-thirds between 1990 and 2015. This can be achieved by urgently addressing the socio-economic, maternal, demographic and environmental determinants of child survival.

One of the determinants of child morbidity and mortality is the "child rearing practices." Socioeconomic environment, child rearing practices and nutrition and health status play a synergistic role that can alter growth and development of a child. ${ }^{[2-4]}$ The reasons usually cited for the poor state of infant and child health in India are inadequate neonatal care, insufficient breastfeeding, malnutrition, low immunity and high incidence of communicable diseases. Public health programs that aims to reduce child morbidity and mortality will be successful only by involving the mother who is the primary care taker of the child. Thus, child rearing practices and mothers' knowledge about breast feeding, complementary feeding, common illness and immunization becomes important. Large population based surveys like the National Family Health Survey-3 (NFHS-3), 2005-06 $6^{[5]}$ has shown that knowledge and practices are associated with literacy. India is culturally diverse and practices differ from region to region. Hence, it is important to understand the local practices to comprehend fully the determinants of child morbidity. This study aimed to assess the knowledge and practices regarding child rearing 
and to study their association with literacy among married women attending out-patient department (OPD) of three primary health centers (PHC) in rural Tamil Nadu, India.

\section{MATERIALS AND METHODS}

Tamil Nadu located in the South-Eastern part of the country is the sixth largest state in India, in which Madurai is one of the largest districts. Three rural PHCs namely Kallanthiri, Chekkanoorni and Poovandi in the district of Madurai were selected for this study. A cross-sectional approach was used to collect information by exit interviews from married women attending OPDs. Each PHC covers about thirty thousand population with an average daily female OPD attendance 50-60. Data was collected during December, 2009 using pretested semi-structured questionnaire that contained questions on socio-demographics, child immunization, breast feeding and other child rearing related practices. Immunization was considered complete if the child was given all age appropriate vaccines until date. The socioeconomic status was recorded according to the Modified Prasad's Scale. ${ }^{[6]}$ Married women in the reproductive age group with the youngest child in the age group of 1-5 years were eligible for inclusion in the study. Women who were primigravida or having youngest child less than 1 year of age, or having children more than 5 years of age (to avoid recall bias) were excluded. The study was conducted in compliance with "ethical principles for medical research involving human subjects" of Helsinki declaration. Confidentiality of information from each participant was ensured and probable ethical concerns were discussed prior to starting the survey. The study participants were explained the purpose of the study and informed consent was obtained from them. To assess the child rearing knowledge and practices (CRKP), a composite score was calculated based on 10 variables namely - (1) Mother knows the importance of breast feeding, (2) Mother has correct knowledge about ideal duration of exclusive breast feeding, (3) Breast feeding for the youngest child was started within one hour of birth, (4) Duration of breast feeding for the youngest child was $\geq 6$ months, (5) Weaning for the youngest child was started at 6 months, (6) Mother knows the importance of immunization to the child, (7) Mother knows the names of common childhood illnesses, (8) Mother has correct knowledge regarding treatment of diarrhea, respiratory infection and malnutrition (9) Mother has no male child preference, (10) Immunization of the youngest child was complete until date. The final score was then categorized into satisfactory and unsatisfactory based on a cut-off of $80 \%$ of the maximum possible score. Statistical analysis like Chi-square test and test for trend were applied wherever applicable and a $P$ value of $<0.05$ was considered significant. All analyses were done using Statistical Package for Social Scientists (SPSS) Statistics version 17.0 (SPSS Inc., Chicago).

\section{RESULTS}

A total of 100 eligible married women were included in the study. About half of the women were in the age group of 25-35 years, $80 \%$ belonged to social class V and VI majority (63\%) were literate and $70 \%$ had $\geq 2$ children [Table 1 ].
Overall $56 \%$ of women had satisfactory CRKP score. Only 5\% of illiterate women had a satisfactory CRKP score as compared with $67 \%$ and $90 \%$ among women who had $1-5$ years of schooling and $>5$ years of schooling respectively [Table 2]. With the increase in literacy status, there was an increase in the proportion of women who had satisfactory CRKP (Chi-square for trend $\left.\chi^{2}=59.8 ; P<0.001\right)$.

In total, $53 \%$ of women had given pre-lacteal feeds (for the youngest child, to reflect the most recent behavior). Among illiterate women, $81 \%$ had given pre-lacteal feeds as compared with 53\% and 38\% among women who had 1-5 years of schooling and $>5$ years of schooling respectively [Table 2]. As the literacy status increased the proportion of women who had given pre-lacteal feed decreased (Chi-square for trend $\chi^{2}=21.5 ; P<0.001$ ).

Among women who had three children, 15 out of 39 (38\%) had fully immunized their first child as compared with 25 out of 39 $(64 \%)$ for the second child and 38 out of $39(97 \%)$ for the third child. Immunization coverage increased as the birth order increased (Chi-square for trend $\chi^{2}=28.9 ; P<0.001$ ).

\begin{tabular}{lc} 
Table 1: Socio-demographic profile of the \\
participants $(n=100)$ \\
\hline Variables & Percentage \\
\hline Age group (years) & 41 \\
$15-25$ & 51 \\
$26-35$ & 8 \\
$36-45$ & \\
Social class (modified Prasad's class) & 20 \\
IV & 40 \\
V & 40 \\
VI & \\
Literacy & 37 \\
Illiterate & 15 \\
1-5 years of schooling & 48 \\
$>5$ years of schooling & \\
No. of children & 30 \\
Single child & 31 \\
Two children & 39 \\
Three children & \\
\hline
\end{tabular}

\begin{tabular}{|c|c|c|}
\hline $\begin{array}{l}\text { Literacy } \\
\text { status }\end{array}$ & $\begin{array}{c}\text { No. of women with } \\
\text { satisfactory CRKP (\%) }\end{array}$ & $\begin{array}{c}\text { No. of women who gave } \\
\text { pre-lacteal feed (\%) }\end{array}$ \\
\hline Illiterate & $2(5)$ & $30(81)$ \\
\hline $\begin{array}{l}1-5 \text { years of } \\
\text { schooling }\end{array}$ & $10(67)$ & $8(53)$ \\
\hline $\begin{array}{l}>5 \text { years of } \\
\text { schooling }\end{array}$ & $44(90)$ & $15(38)$ \\
\hline \multicolumn{3}{|c|}{ CRKP-Child rearing knowledge and practices } \\
\hline
\end{tabular}


Among both literates and illiterates alike, the immunization coverage increased for the second and third child as compared with the first child, but the trend was statistically significant only for illiterate women and not for literate women [For illiterate women, Chi-square for trend $\chi^{2}=8.9 ; P=0.002$. For literate women, Chi-square for trend $\chi^{2}=0.26 ; P=0.6$, Table 3].

\section{DISCUSSION}

This study was able to determine the child rearing practices of mothers of lower socio-economic class attending government PHCs. This study also provides a window to examine the extent to which health services have been able to influence child rearing practices of these women.

It was seen that more educated women had better child rearing practices and that there was also a significant increasing trend in the CRPK score with the increase in the literacy status from being illiterate to having more than 5 years of schooling. A number of studies have also come to a similar conclusion that maternal education was associated better breast feeding practices..$^{[7-9]}$

A trend was also apparent in the practice of giving pre-lacteal feeds with more illiterate women giving pre-lacteal feeds, which is considered an unfavorable practice in new born care. NFHS-3 data ${ }^{[5]}$ shows that the practice of giving pre-lacteal feeds was higher illiterate mothers $(67.5 \%)$ as compared with literate mothers (51.4\%).

There was an interesting observation with regard to completeness of child immunization and birth order. First of all, there was increase in the proportion of children completely immunized with increasing birth order, i.e., the second or third child was in a better position to get full immunization as compared to the first child. The trend was more apparent for illiterate women than for literate women. Literate women were as likely to give full immunization to the first as compared to the third child. However, as far as illiterate women were concerned, the second child and more so the first child were at an unreasonable disadvantage in terms of receiving full immunization as compared to the third child. Repeated contact with health service functionaries for reasons like delivery, attending OPD, out-reach activities aimed to increase awareness may be some of the reasons that might have resulted in this trend. A study from India also showed that maternal education had a significant role in the immunization coverage of children. ${ }^{[10]}$ Many studies carried out outside India also have documented the role of maternal education in the vaccination coverage of children. ${ }^{[1-17]}$ NFHS-3 data ${ }^{[5]}$ shows that

\begin{tabular}{|c|c|c|c|}
\hline \multirow{2}{*}{$\begin{array}{l}\text { Literacy } \\
\text { status }\end{array}$} & \multicolumn{3}{|c|}{ No. of women who gave full immunization for the } \\
\hline & $1^{\text {st }}$ child (\%) & $2^{\text {nd }}$ child (\%) & $3^{\text {rd }}$ child (\%) \\
\hline Illiterate & $25 / 37(68)$ & $30 / 36(83)$ & $31 / 32(97)$ \\
\hline Literate & 55/63 (87) & 30/34 (88) & $7 / 7$ (100) \\
\hline
\end{tabular}

Numerator indicates no. of mothers who have given full immunization and denominator indicates total no. of mothers in that group immunization was higher among children of literate mothers $(51.8 \%)$ as compared with children of illiterate mothers $(26.1 \%)$.

This study has certain limitations. The convenience sampling strategy and the small size limit generalization of the results beyond the community studied. Significant associations found in this study might also be explained by confounding due to unmeasured variables such as partner's literacy, influence of contact with peripheral health functionaries and local Information, Education and Communication (IEC) activities.

In conclusion, it can be stated that mothers' education has a significant role in determining her child rearing practices, which in turn would lead better child survival. The government should give more emphasis to improving maternal education as a long-term strategy in controlling child morbidity and mortality, apart from focusing on measures like improving new born care and childhood disease management.

\section{ACKNOWLEDGMENTS}

We would like to acknowledge the constructive comments given by Dr. Joy Patricia at the design stage.

\section{REFERENCES}

1. United Nations Inter-Agency Group for Child Mortality Estimation. Levels and Trends in Child Mortality. New York: Unicef; 2012.

2. Vazir S, Naidu AN, Vidyasagar P. Nutritional status, psychosocial development and the home environment of Indian rural children. Indian Pediatr 1998;35:959-66.

3. Vasir S, Bogle S, Naidu A. Influence of psychosocial factors on nutritional status of preschool children. J Indian Acad Appl Psychol 1998;14:1-8.

4. Bhogle S. A study of weaning practices, socio economic status and their effect on the anthropometric measures of babies. J Hum Dev 1998;42:18-20.

5. International Institute for Population Sciences (IIPS) and Macro International. National Family Health Survey (NFHS-3), 2005-06: India. Vol. I. Mumbai: IIPS; 2007.

6. Prosad BG. Changes proposed in the social classification of Indian families. J Indian Med Assoc 1970;55:198-9.

7. Kimani-Murage EW, Madise NJ, Fotso JC, Kyobutungi C, Mutua MK, Gitau TM, et al. Patterns and determinants of breastfeeding and complementary feeding practices in urban informal settlements, Nairobi Kenya. BMC Public Health 2011;11:396.

8. Setegn T, Gerbaba M, Belachew T. Determinants of timely initiation of breastfeeding among mothers in Goba Woreda, South East Ethiopia: A cross sectional study. BMC Public Health 2011;11:217.

9. do Nascimento MB, Reis MA, Franco SC, Issler H, Ferraro AA, Grisi SJ. Exclusive breastfeeding in southern Brazil: Prevalence and associated factors. Breastfeed Med 2010;5:79-85.

10. Phukan RK, Barman MP, Mahanta J. Factors associated with immunization coverage of children in Assam, India: Over the first year of life. J Trop Pediatr 2009;55:249-52.

11. Shaikh S, Taj TM, Kazi A, Ahmed J, Fatmi Z. Coverage and predictors of vaccination among children of 1-4 years of age in a rural sub-district of Sindh. J Coll Physicians Surg Pak 2010;20:806-10.

12. Nankabirwa V, Tylleskär T, Tumwine JK, Sommerfelt H, Promise-ebf Study Group. Maternal education is associated with vaccination status of infants less than 6 months in Eastern Uganda: A cohort study. BMC Pediatr 2010;10:92.

13. Abuya BA, Onsomu EO, Kimani JK, Moore D. Influence of maternal education on child immunization and stunting in Kenya. Matern Child Health J 2011;15:1389-99. 
14. Kunwar S, Faridi MM, Singh S, Zahra F, Alizaidi Z. Pattern and determinants of breast feeding and contraceptive practices among mothers within six months postpartum. Biosci Trends 2010;4:186-9.

15. Sullivan MC, Tegegn A, Tessema F, Galea S, Hadley C. Minding the immunization gap: Family characteristics associated with completion rates in rural Ethiopia. J Community Health 2010;35:53-9.

16. Bondy JN, Thind A, Koval JJ, Speechley $\mathrm{KN}$. Identifying the determinants of childhood immunization in the Philippines. Vaccine 2009;27:169-75.

17. Huq MN, Tasnim T. Maternal education and child healthcare in
Bangladesh. Matern Child Health J 2008;12:43-51.

How to cite this article: Abdulkader RS, Kankaria A, Roy R, Chellaiyan VG, Kharya P, Upadhyay RP, Chinnakali P. Knowledge and practices regarding child rearing and its association with literacy among married women in a rural area of Tamil Nadu, India. Int J Med Public Health 2013;3:313-6.

Source of Support: Nil, Conflict of Interest: None declared. 